\title{
Analysis on advantages and disadvantages and countermeasures of the "Internet + International Settlement"
}

\author{
Qiran Yang \\ International Economy and Trade Institution, Jilin University of Finance and Economics, Changchun 130117, China
}

\begin{abstract}
With the global economic integration and rapid development of Internet, big data, cloud computing and other technologies, the government developed "Internet +" action plan, therefore "Internet +"international trade has become a general trend. As an important part of international trade, great changes have taken place in international settlement. Contextualized in the "Internet,+ " this paper analyzed the changes in the international settlement and summarizes the positive and negative impacts of these changes. Finally, the author proposes strategies to cope with the malpractices brought by the changes and defects in the development of international settlement in China.
\end{abstract}

\section{Changes in international settlement in the context of the "Internet+"}

Under the "Internet + " background, significant changes have taken place in international trade settlement. If we regard international trade as a chain in which information, capital, and logistics can be generated, transmitted, and received, the capital, whose contents and form is payment and settlement, plays an important role as a connecting link between the preceding and the following. In the context of the "Internet+," the traditional means of international settlements, such as remittance, collection and letter of credit have changed dramatically in order to meet the needs of all parties in the trade chain. As there are many kinds of businesses and numerous related parties, besides, similarities exist in different means of settlement, the author only takes letter of credit which is relatively complicated and has high international recognition as an example.

\subsection{Applicable rules}

In practical business, there is a large gap between paper documents and electronic documents. The development of e-commerce and electronic letter of credit raises a new need for international trade rules and practices. The International Chamber of Commerce formulated and replenished new rules for electronic presentations on the basis of Uniform Customs and Practice for Documentary Credits, ICC Publication No.500 ( UCP500 ) and introduced Supplement to UCP500 for Electronic Presentation in force as of April I ,2002 Version 1.0 (eUCP1.0). Later, after the introduction of UCP600 in 2007, ICC introduced eUCP1.1.

a Corresponding author: guotianbao1999@126.com
eUCP1.1 does not replace or modify UCP600 but replenishes it. If it is indicated in the letter of credit that the settlement is subject to eUCP, it should be treated as supplementary rules of UCP; when they lead to different results, eUCP prevails. eUCP established the norms and standards of opening and examining electronic letters of credit and gave new interpretations of traditional terms: "surface" means the contents of an electronic record; "place for presentation" means the electronic address of the connection. In addition, eUCP explains the format of electronic records, presentations, examinations, notifications of rejection, dates of issuance, damages to electronic records and so on.

\subsection{Operating platforms}

The main bodies of electronic letter of credit business are mainly divided into two types: commercial banks and e-commerce companies.

\subsubsection{Commercial banks' electronic letter of credit business}

This type of business is similar to traditional credit business programs; the difference lies in the whole electronic procedure. Buyers and sellers negotiate, place orders, and sign contracts through the EDI system; then the entire process of exporters' accepting can be finished over a network. For example, the online letter of credit business of China Merchants Bank provides member enterprises with uniform connected interface, the buyers in a transaction can apply to the issuing, buyers and sellers can receive the information as soon as issuing and start to execute the contract. But the submittal and 
examination of the documents still need to be dealt with at the counter. Accordingly, this type is not completely electronic.

\subsubsection{E-commerce companies' electronic letter of credit business}

In the business of electronic presentations, in addition to using the Bank's own systems, a third-party platform is also required, where the electronic data can be exchanged and the electronic documents can be circulated. Currently there are three most influential international platforms: Trade card Systems in New York, Bolero System whose main business place locates in London, and CCEWebSystem developed by an e-commerce software company. From the perspective of process and substance, only Bolero System realizes the electronization of letter of credit.

Bolero System was initiated by the European Community and established by TTCLUB (Though Transport Club) and SWIFT. With its operation system supported by the Internet, Bolero is an electronic network system whose master architecture is CMP (Central Message Platform). Bolero has open, neutral, and highly secure features; it aims to solve the issue of the electronization of trade documents. Without involvement in the sale process, it trades through a secure and neutral e-commerce transaction platform so that documents can be delivered and exchanged in an electronic environment. The Title Registry Database can transfer ownership of the goods online to replace the functions of the traditional bills of lading. Bolero followsUCP600 and eUCP1.1 rules and its own rules. It is the most professional and mature platform for international electronic presentations.

\subsection{Business processes}

In the context of the "Internet+International settlement," the $\mathrm{L} / \mathrm{C}$ operation process becomes easier because of the electronic and paperless settlements. The procedure of traditional documentary letter of credit is complex, while it is different in electronic letter of credit:

Buyers can use computers to generate issuing applications or visit the issuing bank web page to download the universal format, then present an application for issuing through the connection with Bolero on the Internet. Issuing bank opens an electronic credit following eUCP and indicates the specific provisions for electronic presentation;

Beneficiary receives letter of credit through advising bank, and transmits the electronic documents to presenting bank through Bolero Platform, presenter then transmit the documents to issuing bank through Bolero Platform;

Upon receipt of electronic documents, issuing bank examines the documents and informs the importer of the results of service and examination;

After payment or acceptance, the issuing bank modifies the ownership registration of $\mathrm{B} / \mathrm{L}$ on Bolero platform and transmits the documents to importers;
Importers transmit the electronic documents through Bolero to handle clearance and delivery.

The above process realizes the completely electronic from issuing to payment with easy operation, low cost, and efficient operation.

\section{The advantages and disadvantages of "Internet + international settlement"}

\subsection{The advantages of the changes in international settlement}

\subsubsection{Electronic documents can be settled faster, which improves the efficiency of information utilizing}

Use of electronic documents in circulation reduces the impact of human factors and shortens the delivery time from up to 10 days with traditional documents to just hours or even minutes. According to Bolero platform, collection in traditional $\mathrm{L} / \mathrm{C}$ mode normally takes 21 days, but the whole process of electronic letter of credit can be completed within just 7 days.

Besides the swift delivery speed, data entry is also faster. Different types of documents do not need to repeat the same data in entry, which reduces the complexity of duplication and greatly improves document processing speed, as well as efficiency of data and other information utilizing.

\subsubsection{Paperless information transfer reduces document cost and achieves "low-carbon economy"}

The paperless documents expedites processing speed; Enterprises can negotiate or finance when the electronic bills of lading are issued, which increases circulation speed of documents, funds and logistics, so as to reduce costs and make faster and more profits.

The cost of making and processing paper documents should not be underestimated. Statistics from IATA (International Air Transport Association) show that the cost of processing paper documents in each air waybill is 30 dollars; production of paper documents in a year costs 10 billion dollars. Paperless document delivery will significantly reduce the processing costs. As regards electronic letters of credit only, paperless documents will save $3-7 \%$ cost for exporters.

In addition, paperless documents can substantially save resources, which is in line with "low-carbon economy" trend. Its driving effect on customs, commodity inspections, logistics, banksand so on can also help to achieve a widerlow-carbon economy.

\subsubsection{Reduce errors in document processing and reduce risks of trading fraud}

The traditional settlement process mostly uses manual operation, thus errors are inevitable. Electronic processing and automatic examination greatly reduce the error rate. 
International practices require commercial banks to do settlement process on the principle of strict compliance, besides, manual defects also give criminals a chance. However, electronic documents are stored in related-parties' systems form being issued. These systems have their own protective measures, they can also inspect whether the date and additional information have been tampered with by comparing data with original data through network connection. In this way, electronic presentation can effectively reduce the trading fraud.

\subsubsection{Improve the level of management by monitoring the whole process of trade}

In the process of international settlement finished on the Internet, electronic data is exchanged, so the whole trading process is under the monitoring of users. The data of settlement can be extracted from the system accurately and automatically; it helps enterprises to improve the management level and to realize the information-based decision-making. Thus the "Internet + International settlement" makes the supply chain management play a greater efficiency; it has become a solid basis for scientific decision-making and management.

\subsection{The disadvantages of the changes in international settlement}

\subsubsection{Electronic documents hide security risks}

Under the "Internet +" background, the production, delivery and examination of documents rely on electronic information tools, so tampering, destruction and forgery of documents get easier, and it is difficult to guarantee the integrity, identification, tamper-proofing and confidentiality of the information. In addition, there exist some security issues such as false identities, frauds by electronic means, repudiations of transaction, and invalid documents.

Although the delivery of electronic documents requires encryption, and private key encryptions or public key encryptions ensure the confidentiality and integrity of information, while wide application of these technologies will not be easy; a variety of encryption technologies are also easy to produce compatibility problems, and encryption technologies are usually controlled by states.

To deal with security issues, Tradecard, Bolero and CCEWeb all adopt membership-based transactions. Though frauds and other security risks can be effectively prevented in this way, this closed-end operation is bad for promotion of electronic presentation. Besides, the prevention of security risksinopen environment remains a thorny issue.

\subsubsection{Paperless transactions bring blind areas of law to a certain extent and may lead to legal disputes}

Traditional laws and practices basically put "paper trade" as a starting point, but the traditional trade standards for physical products or serviced not apply to new trade patterns in the context of the "Internet+". For new methods of settlement and electronic documents, slow development in international legal norms leads to blind areas of law.

The legal base for transferring of real rights on Bolero System is sale contracts signed by users, but risks of this kind of real right transfer have to be bear by beneficiaries, which increases the possibilities of legal disputes. As for the third party who is not a member, the validity of transfer of real rights is not provided in Chinese laws, which increases the uncertainty of beneficiaries' collection. In addition, the standard of document formats is far from complete in practices and laws, which makes it easy for trade parties to have legal disputes because of responsibility problems caused by inconsistent formats.

\subsubsection{Easy to lead to monopolies and unhealthy competitions which are not conducive to the development of small and medium enterprises}

Under the "Internet + " background, the emergence of e-commerce breaks through the high threshold of international trade for many small and medium enterprises, but changes took place in international settlement limit the development of small and medium enterprises to some extent.

In process of the" Internet + international settlement," electronic documents need to have standard formats and channels to be examined and transferred successfully, while the commercial banks cannot meet this demand because of the limited energies and skill level. A number of international institutions and companies, such as SWIFT and Bolero, fill this gap. These influential platforms often become the preferred in international settlement. To control risk, these systems often use membership, so the access conditions are high, many small and medium shipping companies, insurance companies, commodity inspection agencies, and other enterprises cannot meet the member requirements, which greatly constrains the development of small and medium as well as the development of e-commerce and international trade.

\subsubsection{Banks will face new challenges and risks}

With rapid development of the "Internet + international settlements," as an extension of international trade, the development of international trade financing lags behind the changes international settlement and lacks innovation. The formation of supply chains in some fields makes the relationship between buyers and sellers get closer; the traditional relationship no longer exists. This change requires banks to provide new international settlement services to enable real-time data delivery and dynamic analysis. But banks just supply trade financingtosingle links in the supply chain through some traditional ways. It is a new challenge for banks that do well in derivative businesses of international settlement under new trade models.

In the case of electronic presentation, the acceleration of trade process has an impact on the financing 
arrangement of importers, which increase the customer's credit risk to banks. In traditional settlement way, it takes a long time to complete settlement, so customers have enough time to arrange funds. However, presentations through the network only need one day. Besides, examining time for bank is shorten due to the specification in eUCP1.1, thus importers have to prepared funds in a short time; It may lead to problems of customers' funds chain, especially for large funds. In that way, delayed payments may happen, so banks will face losses of reputation.

\section{Countermeasures of the changes in international settlement in the context of the "Internet+"}

\subsection{Improve the security of e-commerce environment}

The security of new international settlement models depends on the security of the entire e-commerce environment. To ensure the integrity, identification, tamper-proofing and confidentiality of electronic documents, it is necessary to select the network security technologies in line with China's national condition and the level of technological development. There is no doubt that the best choice is to develop our own network security products.

As for the security of clearing platforms and their connections, enterprises should develop or buy some famous private clients and software, install antivirus software, set up the firewall, and invite some professionals to encrypt the network to maximize the protection.

\subsection{Perfect the system of laws and rules of e-commerce and electronic presentation}

To cope with the legal blind areas in paperless international settlement, the system of laws and rules of e-commerce and electronic presentation should be perfected as soon as possible to make up for the shortcoming in laws and to reduce the possibility of legal disputes.

First, a series of systems should be established for the formation of legal electronic environment; then provide an open, reasonable and legitimate e-commerce environment for the development of international settlement. Secondly, the format and application standards of electronic documents should also be set in related regulations and regulatory documents as soon as possible. As for our legal system, Chinese government has formulated a number of regulations on electronic financial, such as the Electronic Signature Act and the Management Measures of Electronic Banking, but electronic instruments and electronic letters of credit still lack relevant laws and regulations. Therefore, introducing this part of laws as soon as possible can pave the way for the electronization of international settlement in China.

\subsection{Advance the international settlement in electronic method step by step}

In order to achieve the completely electronization, we should promote customers to integrate their systems with the third-party platforms like BoleroSystem. Because the access condition of Bolero system is high, it is feasible to let those eligible customers and businesses connect firstly, and try to create conditions for enterprises and organizations that cannot reach the standard. As for the expensive membership fee of BoleroSystem, exporters can join in by bundling into group to reduce the membership fee for each member.

\subsection{Banks should explore the innovation and reengineering of electronic presentations business process and service functions}

In order to improve the efficiency of document processing and to control risks, a number of banks establish document processing centers and centralize processing of documents. Now, the Bank of China has developed electronic business with BoleroSystem. But take into account the security of system and the urgency of business, electronic documents is still transferred from Bolero system to the Bank's own systems manually in the first business.

In view of this, banks should actively explore the reengineering of electronic presentation business process, considerate how to share information in the banking system with third-party platforms and how to reduce manual operations in document transfers. Furthermore, banks can try to dock banking systems with third-party platform systems to achieve completely electronization.

Commercial banks can try to provide a transition from the traditional "node" service to "one-stop" service in electronic settlement. International settlement business can be extended to trade finance services of international trade supply chain, which can gain maximum profit from deepening the services. In addition, banks should cooperate with electronic trade finance service providers to develop new products for international settlements on the basis of improving the settlement businesses.

\subsection{Speed up the training of professionals}

The country should also carry out multi-level, multi-channel, and multi-form talent training which depends on the efforts of governments, universities, enterprises, and other aspects. In addition, training current personnel engaged in international settlement with a competent curriculum will meet immediate needs. To accomplish this, corresponding majors and curriculums should be established to build a solid foundation for the long-term development of international settlement.

\section{References}

1. R. Arora, D.K. Banwet, Asia-Pacific Development Journal. 10, 69 (2003). 
2. Y. Chen, C. Li, Business times. 10, 70-72 (2006).

3. Y.F. Cheng, Shenyang University of technology, (2009).

4. F. Gai, Shandong University of finance, (2015).

5. Q. Liao. International financial. 06, 28-33 (2014).
6. Q.H. Meng, Business Culture (the first half). 05, 246-247 (2011).

7. J.X. Wang, Of finance. 01, 30-32 (2007).

8. J.P. Zhou, East China Normal University, (2006).. 